\title{
APPLICATION OF STUDSVIK'S CMS5 CODE SYSTEM TO ACCIDENT TOLERANT FUEL CORE DESIGN AND ANALYSIS
}

\author{
Gerardo Grandi ${ }^{1}$, Rodolfo Ferrer ${ }^{1}$, and Tamer Bahadir ${ }^{2}$ \\ ${ }^{1}$ Studsvik Scandpower Inc. \\ 1070 Riverwalk Dr., Suite 150, Idaho Falls ID 83402-3345, USA \\ ${ }^{2}$ Studsvik Scandpower Inc. \\ 10 Langley Road, Suite 201, Newton, MA 02459-1972, USA
}

Gerardo.Grandi@studsvik.com, Rodolfo.Ferrer@studsvik.com, Tamer.Bahadir@studsvik.com

\begin{abstract}
The possible deployment of Accident Tolerant Fuels (ATF) for currently-operating Light Water Reactors (LWR) has prompted interest in the use of Studsvik's CMS5 code system to support the analysis of such advanced ATF core designs. Various ATF concepts have been proposed; for example, uranium silicide $\left(\mathrm{U}_{3} \mathrm{Si}_{2}\right)$ fuel, together with iron-based (FeCrAl) cladding. The purpose of this work is to showcase the application of the CMS5 code system, which includes the CASMO5 advanced lattice physics code and the SIMULATE5 three-dimensional nodal simulator, to the analysis of a $\mathrm{U}_{3} \mathrm{Si}_{2} / \mathrm{FeCrAl}$ ATF concept. Given that the CMS5 code system was designed from inception to enable the analysis of advanced core designs, only minor changes to the CASMO5 lattice physics code and SIMULATE5 core simulator are necessary. The current CASMO5 586 energy-group nuclear data library provides all the necessary data to support the generation of homogenized data for downstream use by SIMULATE5 for ATF. The SIMULATE5 nodal code, which features a simplified fuel pin model, requires updating various thermophysical properties corresponding to the $\mathrm{U}_{3} \mathrm{Si}_{2} / \mathrm{SiC}$ ATF fuel and the gaseous conductance models. An equilibrium core for the Integral Inherently Safe $\left(I^{2} S\right)$ LWR design developed by the Georgia Institute of Technology was selected. The results of the CMS5 simulation were compared with those in the literature and were found to be in good agreement, giving us confidence that the CMS5 package can be used in the modeling of LWR systems with ATF technology.
\end{abstract}

KEYWORDS: CASMO5, SIMULATE5, Accident Tolerant Fuel, Silicide Fuel, ODS-Steel Cladding

\section{INTRODUCTION}

The possible deployment of Enhanced Accident Tolerant Fuels (ATF) for currently operating Light Water Reactors (LWR) has prompted interest in the use of Studsvik's CMS5 code system to support the analysis of such advanced ATF core designs. Various ATF concepts have been proposed. For example, uranium silicide $\left(\mathrm{U}_{3} \mathrm{Si}_{2}\right)$ fuel, together with Oxide Dispersion Strengthened ODS iron based (FeCrAl) cladding. The purpose of this work is to showcase the application of the CMS5 code system, which includes the CASMO5 (C5) advanced lattice physics code [1] and the SIMULATE5 (S5) three-dimensional nodal simulator [2] for one of the ATF concepts. Section 2 presents the improvements to the CMS5 codes. In particular, the S5 fuel 
pin model requires updating various thermophysical properties corresponding to the ATF fuel and updating the gaseous conductance models. Section 3 presents the $\mathrm{U}_{3} \mathrm{Si}_{2} / \mathrm{FeCrAl} \mathrm{ATF}$ concept selected for the analysis with CMS5: an equilibrium core for the Integral Inherently Safe $\left(\mathrm{I}^{2} \mathrm{~S}\right)$ LWR design developed by an international consortium led by the Georgia Institute of Technology [3]. Section 4 compares key results for two different $\mathrm{I}^{2} \mathrm{~S}$ designs: one based on an $\mathrm{UO}_{2}$ fuel and another on the $\mathrm{U}_{3} \mathrm{Si}_{2}$ concept, which discusses the modifications to the CMS5 codes. Finally, some conclusions are drawn in section 6 .

\section{CMS5 MODEL IMPROVEMENTS}

\subsection{CASMO5 Improvements}

Given that the CMS5 code system was designed from its inception to enable analysis of advanced core designs, only minor changes to the $\mathrm{C} 5$ lattice physics code and S5 core simulator are necessary. The current C5 586 energy-group nuclear data library based on ENDF/B-VIII.0 [4] provides all the necessary data to support the generation of homogenized data for downstream use by S5 for ATF. However, the results presented in this work are based on the current ENDF/B-VII.1 nuclear data library.

\subsection{SIMULATE5 Improvements}

The ATF concepts introduce high performance $\mathrm{UO}_{2}$ pellets (i.e., chromium-doped pellets) and high-density fuel (e.g., $\mathrm{U}_{3} \mathrm{Si}_{2}, \mathrm{UN}$ ). The high performance $\mathrm{UO}_{2}$ pellets can achieve higher densification (96 to $97 \% \mathrm{TD}$ ) and higher fission gas retention into the fuel matrix [5]. The $\mathrm{UO}_{2}$ thermal conductivity enhancement from higher fuel densities can be modeled using the NFI correlations as documented in reference [6]. Of the different high-density fuels, only $\mathrm{U}_{3} \mathrm{Si}_{2}$ has been considered so far, but other materials (e.g., UN) can be easily added into $\mathrm{S} 5$. The replacement of the $\mathrm{UO}_{2}$ by $\mathrm{U}_{3} \mathrm{Si}_{2}$ impacts both the pellet thermal conductivity and the fuel/clad gap conductance model. Fig. 1 compares key material properties of fresh $\mathrm{UO}_{2}[6]$ and $\mathrm{U}_{3} \mathrm{Si}_{2}$ $[7,8]$ that affect the pellet thermal resistance and fuel/clad gap width.
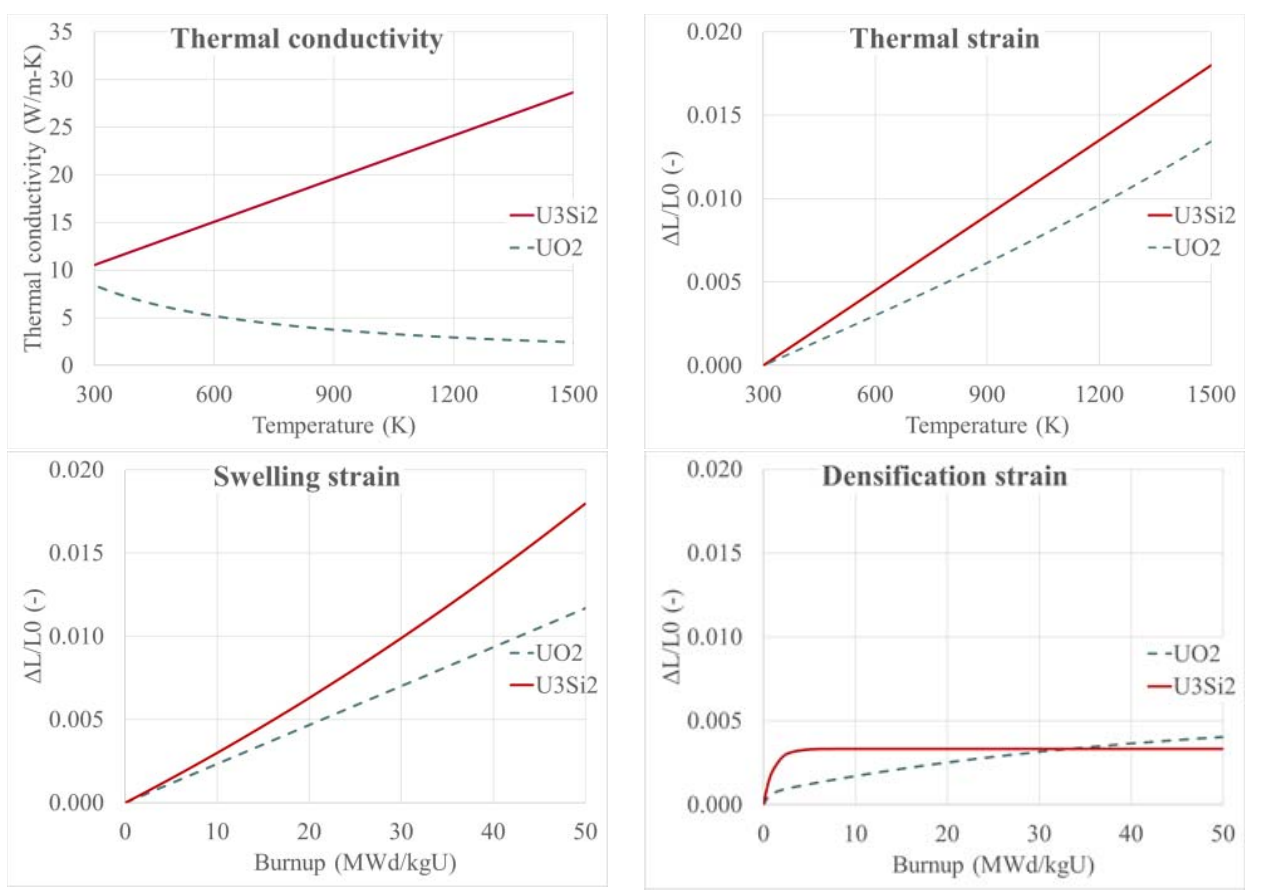

Figure 1. Comparison of $\mathrm{U}_{3} \mathrm{Si}_{2}$ and $\mathrm{UO}_{2}$ thermal conductivity (top left), thermal expansion (top right), swelling (bottom left) and densification (bottom right). 
The following observations can be made from Fig. 1:

- The $\mathrm{U}_{3} \mathrm{Si}_{2}$ thermal expansion is higher than the $\mathrm{UO}_{2}$ thermal expansion for the same temperature.

- $\mathrm{U}_{3} \mathrm{Si}_{2}$ swelling strain is approximately $50 \%$ higher than the $\mathrm{UO}_{2}$ swelling at $50 \mathrm{MWd} / \mathrm{kg}$.

- $\mathrm{U}_{3} \mathrm{Si}_{2}$ and $\mathrm{UO}_{2}$ densification strains are different at BOL. However, at $50 \mathrm{MWd} / \mathrm{kg}$ the densification strains are almost the same.

- S5 fuel pin model accounts for the degradation of the $\mathrm{UO}_{2}$ thermal conductivity with burnup. The degradation of $\mathrm{U}_{3} \mathrm{Si}_{2}$ thermal conductivity with burnup was not found in the open literature. Therefore, it is neglected in the present work.

The ATF designs will introduce cladding coatings [9], thin-wall, high-strength iron alloys cladding (e.g., FeCrAl) [10] and ceramic cladding (SiC) [11]. The thickness of the coatings to the present zirconium alloys (Zircaloy, ZIRLO ${ }^{\mathrm{TM}}$ and $\mathrm{M}^{\mathrm{TM}}$ ) is expected to be in the order of $10-20 \mu \mathrm{m}$. The increase in the cladding thermal resistance due to the coating is very small and it is provisionally ignored in S5. The replacement of the zirconium-based alloys by $\mathrm{FeCrAl}$ or $\mathrm{SiC}$ impacts both the clad thermal conductivity and the fuel/clad gap conductance model. Fig. 2 compares key cladding properties that affect the thermal resistance in the cladding and the size of the fuel/clad gap.
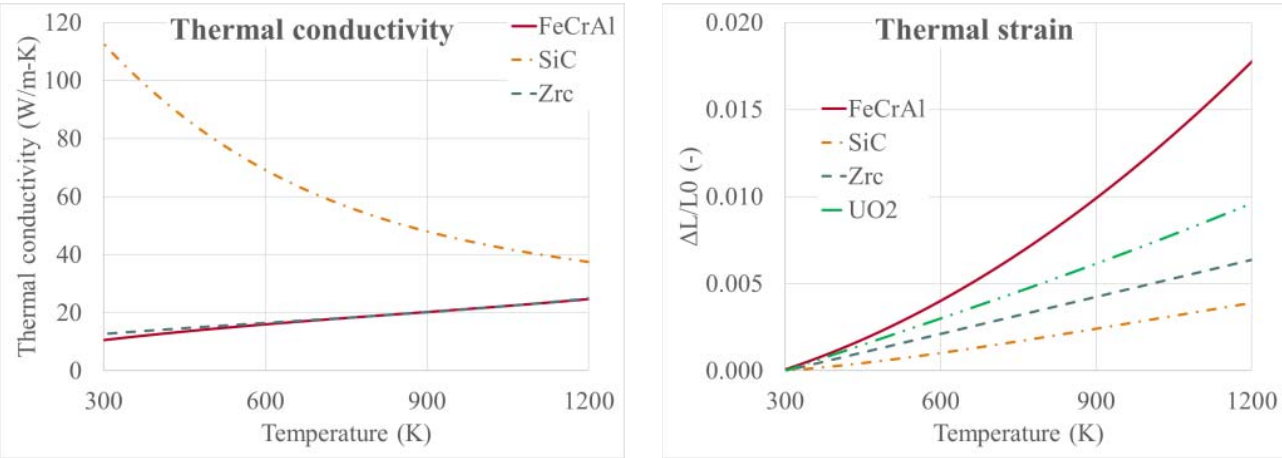

\section{Figure 2. Comparison of $\mathrm{FeCrAl}, \mathrm{SiC}$, and zircaloy thermal conductivity (left) and thermal strain} (right).

The following observations can be made from Fig. 2:

- There is no impact on the thermal resistance with the replacement of zirconium-based alloys by $\mathrm{FeCrAl}$.

- There is an impact on the thermal resistance with the replacement of zirconium-based alloys by SiC. As the cladding thermal resistance is small, the impact on fuel average temperature is not significant.

- For the range of temperatures of interest $(\approx 600 \mathrm{~K})$, the FeCrAl thermal strain is $50 \%$ larger than the zircaloy.

- The thermal expansion of the zircaloy is smaller than the thermal expansion of the $\mathrm{UO}_{2}$. As a result, the cold gap between the fuel pellet and the cladding is reduced at beginning of life (BOL). However, the thermal expansion of $\mathrm{FeCrAl}$ is greater than the thermal expansion of $\mathrm{UO}_{2}$. Therefore, the gap between the UO2 pellet and FeCrAl cladding may not be reduced at BOL.

- The thermal expansion of the $\mathrm{SiC}$ is smaller than the thermal expansion of the $\mathrm{UO}_{2}$. As a result, the cold gap between the fuel pellet and the cladding is reduced at BOL.

The S5 fuel/cladding gap model [12] considers the gaseous conductance through the areas of non-contact and the solid contact conductance through contact areas. The gaseous conductance model considers the following effects: (1) gas conductivity degradation as the result of fission gas release, (b) fuel pellet irradiation swelling and densification, (c) fuel pellet and clad thermal expansion and (d) clad compression caused by irradiation at high pressure. The gaseous conductance may be expressed as follows, 


$$
h_{g}=\frac{k_{g}(1-\xi)}{g+g_{0}+g_{3}}+\frac{k_{g} \cdot \xi}{g_{0}+g_{3}}
$$

$k_{g}$ is the modified thermal conductivity for the gas, $\xi$ is the fraction of the fuel-cladding interface in solid contact, $g$ is the average radial gap, $g_{0}$ is the temperature jump distance for the gas and $g_{3}$ is the fuel roughness. The S5 fuel pin model does not explicitly treat the fission gas release during the life of the rod. Instead, it assumes that the gap is initially filled with helium and a degradation factor, as a function of burnup, models the change of the thermal conductivity from fission gases. It is assumed that the reduction in gas conductivity is independent of the gap and plenum volumes, and to be proportional to the fuel volume and burnup. The proportionality constant depends on the pellet materials (i.e., $\mathrm{UO}_{2}$ or $\mathrm{U}_{3} \mathrm{Si}_{2}$ ).

The Kjaerheim-Roldstad model [12] expresses the relationship between the fraction of fuel-cladding interface in solid contact and the average radial gap,

$$
\xi=C_{2}^{100 \cdot g} / r_{f}
$$

where $C_{2}$ is a model constant and $r_{f}$ is the fuel pellet radius. Finally, the average radial gap dimension is given by,

$$
g=r_{c l}-r_{f p}
$$

Where $r_{f p}$ is the effective fuel pellet radius corrected for thermal expansion, densification and swelling, and $r_{c l}$ is the effective cladding radius corrected for creep-down and thermal expansion. The creep-down is assumed to be proportional to the rod radius and burnup. The proportionality constant depends on the cladding materials (i.e., Zircaloy, $\mathrm{FeCrAl}$ or $\mathrm{SiC}$ ).

\section{DESCRIPTION OF THE PROBLEM}

The $\mathrm{I}^{2} \mathrm{~S}-\mathrm{LWR}$ contains 121 fuel assemblies with an active core height of $365.76 \mathrm{~cm}$. The rated power is $2,850 \mathrm{MWth}$, the rated core flow is $15,500 \mathrm{~kg} / \mathrm{s}$ and the design pressure $15.5 \mathrm{MPa}$. The 3-batch $\mathrm{UO}_{2}$ and $\mathrm{U}_{3} \mathrm{Si}_{2}$ cores designed by Salazar and Franceschini [3] are analyzed in section 4. Both core designs include fresh and burned assemblies as shown in Fig. 3. There are 40 fresh assemblies per reload. The twice- burned assemblies are positioned in the periphery of the core to reduce leakage. The $\mathrm{I}^{2} \mathrm{~S}-\mathrm{LWR}$ has 45 reactivity control cluster assemblies (RCCA) with 24 control rods (Ag-In-Cd) per RCCA. Both the $\mathrm{UO}_{2}$ and the $\mathrm{U}_{3} \mathrm{SI}_{2}$ assembly designs use different enrichments $(4.8,4.65,4.45,3.20 \mathrm{w} \%)$ and integral fuel burnable absorber (IFBA) rods. Three different IFBA patterns (84, 100 and 156 BA rods) were used. 


\begin{tabular}{|c|c|c|c|c|c|c|}
\hline $3 x$ & $1 x$ & Feed & $2 x$ & $1 \mathrm{x}$ & Feed & $2 x$ \\
\hline $1 x$ & $2 x$ & $1 x$ & $1 x$ & Feed & Feed & $2 x$ \\
\hline Feed & $1 x$ & $1 \mathrm{x}$ & $1 x$ & Feed & $2 x$ & \\
\hline $2 \mathrm{x}$ & $1 x$ & $1 x$ & $1 x$ & Feed & $2 x$ & \\
\hline $1 x$ & Feed & Feed & Feed & $2 x$ & & \\
\hline Feed & Feed & $2 x$ & $2 x$ & & & \\
\hline $2 x$ & $2 x$ & & & & & \\
\hline
\end{tabular}

\begin{tabular}{lcc}
\hline Parameter & \multicolumn{2}{c}{ Values } \\
\hline Lattice type & \multicolumn{2}{c}{$19 \times 19$, square } \\
Cladding Material & \multicolumn{2}{c}{ FeCrAl } \\
Number of rods per assembly & \multicolumn{2}{c}{336} \\
Fuel Material & U3Si2 & UO2 \\
Fuel Rod Outer Radius, cm & 0.4572 & 0.4572 \\
Cladding thickness, cm & 0.0406 & 0.0406 \\
Cladding Inner Radius, cm & 0.4166 & 0.4166 \\
Pellet-Clad Gap Width, cm & 0.0152 & 0.0102 \\
Pellet Outer Radius, cm & 0.4013 & 0.4064 \\
Blanket's Pellet Inner Radius, cm & 0.1270 & 0.0000 \\
Full enriched Pellet Inner Radius, cn & 0.1270 & 0.1969 \\
Fuel Density, \% of theoretical & 95.5 & 95.5 \\
Fuel Rod Pitch, cm & \multicolumn{2}{c}{1.1354} \\
\hline
\end{tabular}

Figure 3. $I^{2} S$ Equilibrium cycle core loading pattern and fuel design parameters.

\section{RESULTS}

\subsection{Comparison of $\mathrm{UO}_{2}$ and $\mathrm{U}_{3} \mathrm{Si}_{2}$ Temperatures}

Fig. 4 compares the evolution of temperatures for $\mathrm{UO}_{2}$ and $\mathrm{U}_{3} \mathrm{Si}_{2}$ rods representative of the $\mathrm{I}^{2} \mathrm{~S}-\mathrm{LWR}$ assembly designs. For this evaluation, the Linear Heat Generation Rate (LHGR) is assumed to be $20 \mathrm{~kW} / \mathrm{m}$. The LHGR is assumed to be constant until the rods reach $50 \mathrm{MWd} / \mathrm{kg}$. Rod dimensions are provided in Fig. 3. For the purpose of this comparison the thermal conductivity degradation of the $\mathrm{UO}_{2}$ ceramic material has been neglected. Note that, the cladding thermal expansion and compression under irradiation are the same for the two rods. Therefore, differences in the gap width are from the pellet thermal expansion, swelling and densification. In S5, the cross sections are evaluated with an effective fuel temperature $\left(T_{E F F}\right)$, i.e., weighted average of the volume-averaged temperature $\left(T_{A V E}\right)$, and the pellet surface temperature $\left(T_{S}\right)[13]$,

$$
T_{E F F}=\omega \cdot T_{A V E}+(1-\omega) \cdot T_{S}
$$

where the value of $\omega$ is empirically adjusted to match the reactivity HZP and HFP for a pin cell problem. Fig. 4 (below) shows the surface temperature, the volume-averaged temperature, the maximum temperature and the effective temperature.

The following observations can be made from Fig. 4:

- The surface temperatures are governed by the temperature rise in the fuel-clad gap. The temperature rise in the gap for the $\mathrm{U}_{3} \mathrm{Si}_{2}$ rod at $\mathrm{BOL}$ is $\approx 150 \mathrm{~K}$ higher, because the $\mathrm{U}_{3} \mathrm{Si}_{2}$ rod cold gap is $\approx 50 \%$ larger.

- The surface temperature for the $\mathrm{U}_{3} \mathrm{Si}_{2}$ pellet is greater than the surface temperature of the $\mathrm{UO}_{2}$ pellet. However, the volume-average temperature for the $\mathrm{U}_{3} \mathrm{Si}_{2}$ pellet is lower than the volume-average temperature of the $\mathrm{UO}_{2}$ pellet due to the $\mathrm{U}_{3} \mathrm{Si}_{2}$ higher thermal conductivity.

- The effective fuel temperature is governed by the gap model for the $\mathrm{U}_{3} \mathrm{Si}_{2}$ assemblies and by the gap model and the pellet thermal conductivity for the $\mathrm{UO}_{2}$ assemblies. 

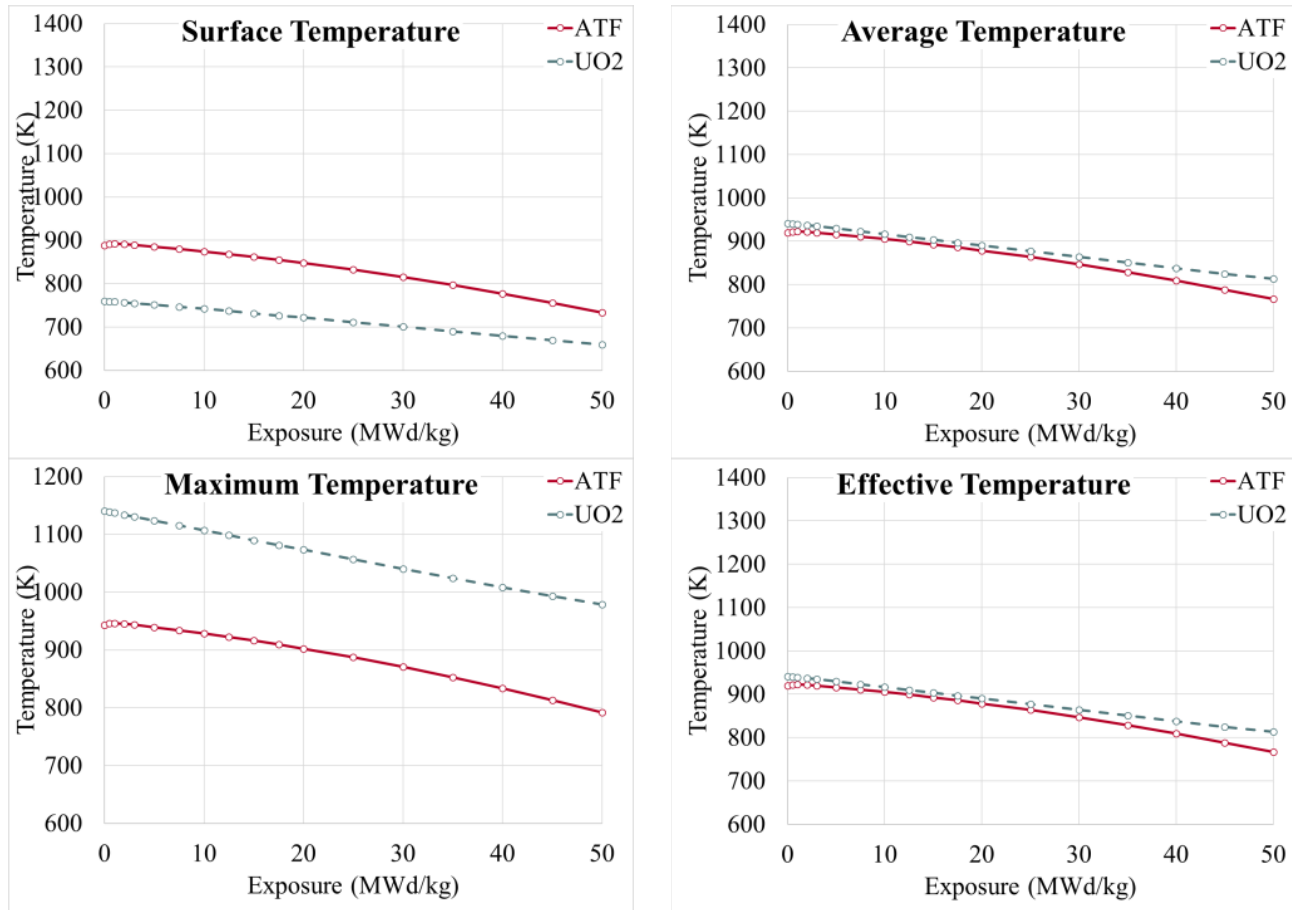

Figure 4. Evolution of rated fuel temperatures as a function of burnup: pellet surface temperature (top left), pellet average (top right), pellet maximum (bottom left), effective (bottom right).

\subsection{Equilibrium Core Analysis}

The assembly burnup distributions for the $\mathrm{U}_{3} \mathrm{Si}_{2}$ and $\mathrm{UO}_{2}$ equilibrium cores are presented in Figs. 5 and 6 , respectively. In addition, the present solutions are compared to the Salazar and Franceschini solution [3]. These authors performed the analysis with the Westinghouse core physics package and a 70-group library based on ENDF BVII.0.

\begin{tabular}{|c|c|c|c|c|c|c|}
\hline 38.48 & 17.16 & 0.00 & 32.61 & 16.77 & 0.00 & 33.61 \\
\hline 17.16 & 32.72 & 18.27 & 15.50 & 0.00 & 0.00 & 30.59 \\
\hline 0.00 & 18.27 & 17.16 & 14.17 & 0.00 & 33.22 & \\
\hline 32.61 & 15.50 & 14.17 & 17.28 & 0.00 & 32.00 & \\
\hline 16.77 & 0.00 & 0.00 & 0.00 & 30.59 & & \\
\hline 0.00 & 0.00 & 33.22 & 32.00 & & & \\
\hline 33.61 & 30.59 & & & & & \\
\hline
\end{tabular}

\begin{tabular}{|c|c|c|c|c|c|c|}
\hline-0.67 & -2.94 & 0.00 & -2.28 & -2.84 & 0.00 & -2.72 \\
\hline-2.94 & -2.09 & -3.13 & -2.08 & 0.00 & 0.00 & -2.24 \\
\hline 0.00 & -3.13 & -2.94 & -1.87 & 0.00 & -2.12 & \\
\hline-2.28 & -2.08 & -1.87 & -1.26 & 0.00 & -2.05 & \\
\hline-2.84 & 0.00 & 0.00 & 0.00 & -1.64 & & \\
\hline 0.00 & 0.00 & -2.12 & -2.05 & & & \\
\hline-2.72 & -2.24 & & & & & \\
\hline
\end{tabular}

Figure 5. $\mathrm{U}_{3} \mathrm{Si}_{2}$ Core equilibrium burnup in CMS5 (left), differences in \% (right). 


\begin{tabular}{|c|c|c|c|c|c|c|}
\hline 40.78 & 18.22 & 0.00 & 34.68 & 18.27 & 0.00 & 36.10 \\
\hline 18.22 & 34.17 & 19.80 & 16.83 & 0.00 & 0.00 & 33.23 \\
\hline 0.00 & 19.80 & 18.22 & 15.68 & 0.00 & 35.43 & \\
\hline 34.68 & 16.83 & 15.68 & 17.48 & 0.00 & 34.01 & \\
\hline 18.27 & 0.00 & 0.00 & 0.00 & 32.13 & & \\
\hline 0.00 & 0.00 & 35.43 & 34.01 & & & \\
\hline 36.10 & 33.23 & & & & & \\
\hline
\end{tabular}

\begin{tabular}{|c|c|c|c|c|c|c|}
\hline 0.27 & -1.46 & 0.00 & -1.08 & -1.62 & 0.00 & -1.12 \\
\hline-1.46 & -0.96 & -1.59 & -0.88 & 0.00 & 0.00 & -1.13 \\
\hline 0.00 & -1.59 & -1.46 & -0.82 & 0.00 & -1.03 & \\
\hline-1.08 & -0.88 & -0.82 & -0.06 & 0.00 & -0.96 & \\
\hline-1.62 & 0.00 & 0.00 & 0.00 & -0.62 & & \\
\hline 0.00 & 0.00 & -1.03 & -0.96 & & & \\
\hline-1.12 & -1.13 & & & & & \\
\hline
\end{tabular}

Figure 6. $\mathrm{UO}_{2}$ Core equilibrium burnup in CMS5 (left), differences in percent (right).

Present results are in reasonable agreement with the solution from reference [3] for both cores. The average differences for the $\mathrm{U}_{3} \mathrm{Si}_{2} / \mathrm{UO}_{2}$ cores are $-1.5 \%$ and $-0.7 \%$, respectively. The maximum differences are $3.2 \%$ and $-1.6 \%$. The differences for the $\mathrm{U}_{3} \mathrm{Si}_{2}$ core are roughly twice the differences for the $\mathrm{UO}_{2}$ core.

The trends of main core parameters, namely Critical Boron Concentration (CBC), Axial Offset (A-O), total power peaking factor $\left(\mathrm{F}_{\mathrm{Q}}\right)$ and radial power peaking factor $\left(\mathrm{F}_{\Delta \mathrm{H}}\right)$ are shown in Fig. 7.
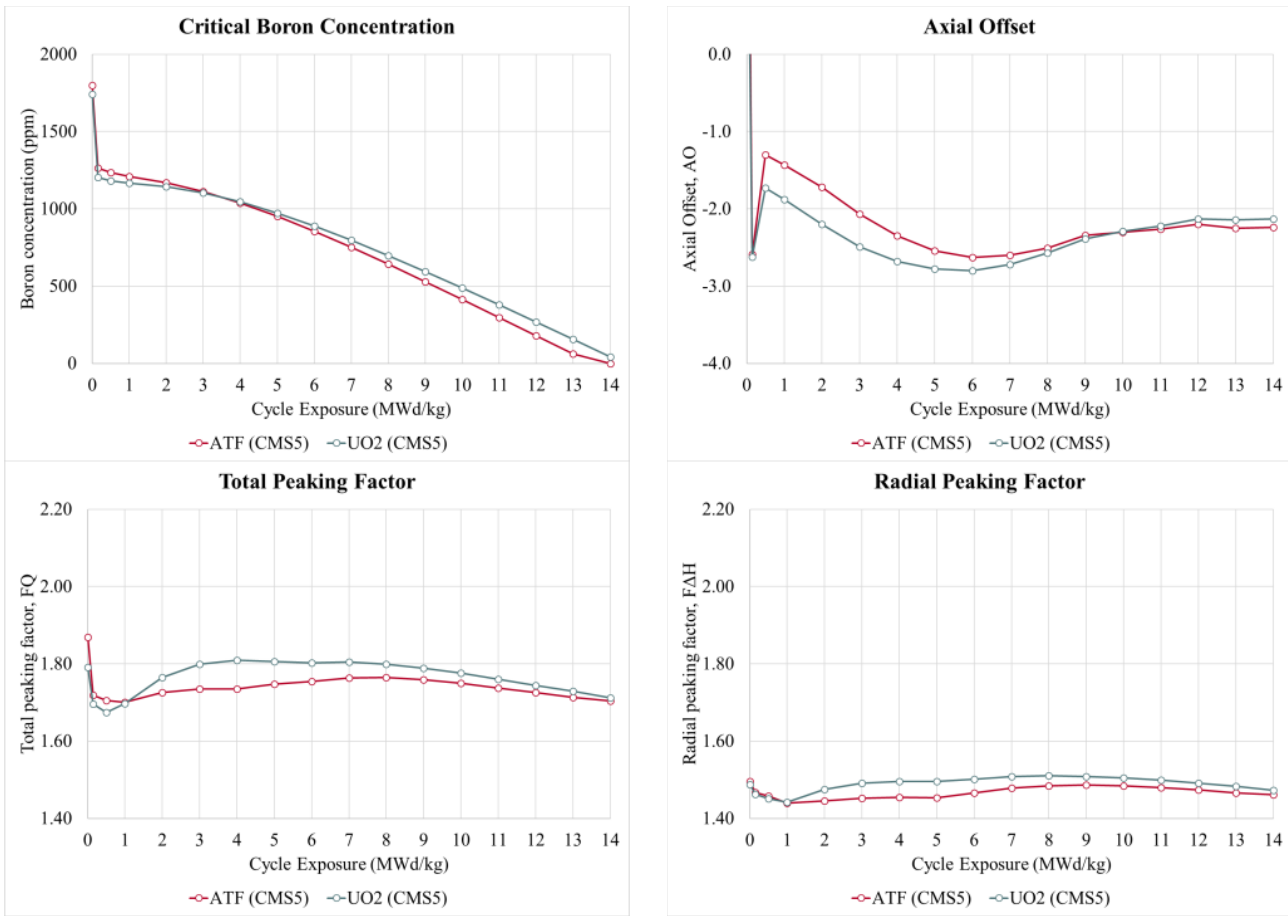

Figure 7. Comparison of the critical boron concentration (top left), axial offset (top right), total peaking factor (bottom left) and radial peaking factor (bottom right). 
The behaviors of the above-mentioned parameters are very much alike for the $\mathrm{U}_{3} \mathrm{Si}_{2}$ and $\mathrm{UO}_{2}$ cores. Similar trends were observed by Salazar and Franceschini [3]. The cycle-peak $\mathrm{F}_{\mathrm{Q}}$ are 1.869 and 1.809 for the $\mathrm{U}_{3} \mathrm{Si}_{2}$ and $\mathrm{UO}_{2}$ cores, respectively. The cycle-peak $\mathrm{F}_{\Delta \mathrm{H}}$ are 1.545 and 1.496. Peaking factors computed by CMS5 are in very good agreement with the values: $\mathrm{F}_{\mathrm{Q}} 1.862$ and 1.892 and $\mathrm{F}_{\Delta \mathrm{H}} 1.526$ and 1.545 from [3].

\section{CONCLUSIONS}

The CMS5 code system was designed from inception to enable the analysis of advanced core designs. The improvements to the S5 fuel pin model extend the capability of CMS5 to analyze ATF cores. Further work is required to verify the present models - especially the gap conductance - against calculations performed with a fuel performance code.

For one of the ATF concepts $\left(\mathrm{U}_{3} \mathrm{Si}_{2}\right.$ fuel and FeCrAl cladding), CMS5 simulations were compared with results provided in the literature. The results were found to be in good agreement, demonstrating confidence that the CMS5 package can be used in the modeling of LWR systems with ATF technology.

\section{REFERENCES}

1. J. D. Rhodes et al., "CASMO-5 Development and Applications", PHYSOR 2006, Vancouver, Canada, (2006)

2. T. Bahadir and S-Ö. Lindahl, "Studsvik's Next Generation Nodal Code SIMULATE5", Advances in Nuclear Fuel Management IV (ANFM 2009), Hilton Head Island, USA, (2009)

3. D. Salazar and F. Franceschini, "I²S-LWR Equilibrium Cycle Core Analysis," PHYSOR 2014, Kyoto, Japan, Sept. 29-Oct. 3 (2014).

4. R. Ferrer and J. Rhodes, "Generation and Initial Validation of a New CASMO5 ENDF/B-VIII.0 Nuclear Data Library,” PHYSOR 2020, Cambridge, UK, March 29 - April 2, (2020).

5. J. Bischoff, et al., "Areva NP's Enhanced Accident-Tolerant Fuel Developments: Focus on Cr-coated M5 Cladding," Nuclear Engineering and Technology, 50, pp. 223-228, (2018).

6. D.D. Lanning et al., "FRAPCON-3 Updates," NUREG/CR-6534, 4, PNL-11513, (2005).

7. K.E. Metzger et al., "Model of $\mathrm{U}_{3} \mathrm{SI}_{2}$ Fuel System Using BISON Fuel Code," ICAPP 2014, Charlotte, NC, USA, April 6-9 (2014).

8. K.A. Gamble et al., "Behavior of $\mathrm{U}_{3} \mathrm{Si}_{2}$ Fuel and FeCrAl Cladding Under Normal Operating and Accident Reactor Conditions," INL/EXT-16-40059, Rev. 0, (2016).

9. I. Younker and M. Fratoni, "Neutronic Evaluation of Coating and Cladding Materials for Accident Tolerant Fuels," Progress in Nuclear Energy, 88 (2016).

10. Y. He et al., "Preliminary evaluation of U3Si2-FrCrAl fuel performance in LWR through a multiphysics coupled way," Nuclear Engineering and Design, 328, 27 (2018).

11. X. Wu et al., "Neutronics and fuel performance evaluation of accident tolerant under normal operation conditions," INL/EXT-14-32591, Rev. 1, (2014).

12. G. Grandi, "SIMULATE5 Fuel Pin Model Description and Verification Against ENIGMA," Proceedings of 2018 LWR Fuel Performance TopFuel Prague, Czech Republic, September 30-October 4, (2018).

13. G. Grandi et al., "Effect of CASMO5 Cross-Section Data and Doppler Temperature Definitions on LWR Reactivity Initiated Accidents", PHYSOR 2010, Pittsburgh, Pennsylvania, USA, May 9-14, (2010). 